\title{
Incorporating Bioenergy in Sustainable Landscape Designs
}

Workshop Two: Agricultural Landscapes

Held at Argonne National Laboratory June 24-26, 2014 


\begin{abstract}
About Argonne National Laboratory
Argonne is a U.S. Department of Energy laboratory managed by UChicago Argonne, LLC under contract DE-AC02-06CH11357. The Laboratory's main facility is outside Chicago, at 9700 South Cass Avenue, Argonne, Illinois 60439. For information about Argonne and its pioneering science and technology programs, see www.anl.gov.
\end{abstract}

\title{
DOCUMENT AVAILABILITY
}

Online Access: U.S. Department of Energy (DOE) reports produced after 1991 and a growing number of pre-1991 documents are available free via DOE's SciTech Connect (http://www.osti.gov/scitech/).

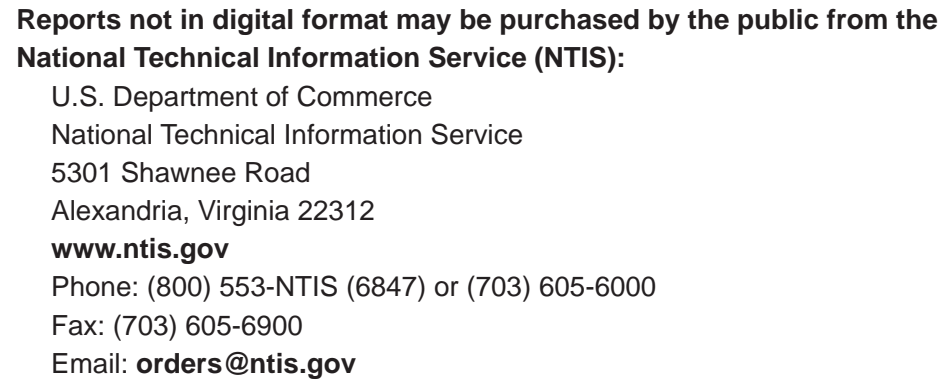

Reports not in digital format are available to DOE and DOE contractors from the Office of Scientific and Technical Information (OSTI):

U.S. Department of Energy

Office of Scientific and Technical Information

P.O. Box 62

Oak Ridge, Tennessee 37831-0062

www.osti.gov

Phone: (865) 576-8401

Fax: (865) 576-5728

Email: reports@osti.gov

\footnotetext{
Disclaimer

This report was prepared as an account of work sponsored by an agency of the United States Government. Neither the United States Government nor any agency thereof, nor UChicago Argonne, LLC, nor any of their employees or officers, makes any warranty, express or implied, or assumes any legal liability or responsibility for the accuracy, completeness, or usefulness of any information, apparatus, product, or process disclosed, or represents that its use would not infringe privately owned rights. Reference herein to any specific commercial product, process, or service by trade name, trademark, manufacturer, or otherwise, does not necessarily constitute or imply its endorsement, recommendation, or favoring by the United States Government or any agency thereof. The views and opinions of document authors expressed herein do not necessarily state or reflect those of the United States Government or any agency thereof, Argonne National Laboratory, or UChicago Argonne, LLC.
} 


\section{Incorporating Bioenergy in Sustainable Landscape Designs}

Prepared by:

M. Cristina Negri and H. Ssegane

Energy Systems Division

Argonne National Laboratory

July 2015

Contacts:

Kristen Johnson, Bioenergy Technologies Office (kristen.johnson@ee.doe.gov)

Mark Elless, Bioenergy Technologies Office (mark.elless@ee.doe.gov)

M. Cristina Negri, Argonne National Laboratory (negri@anl.gov)

Virginia Dale, Oak Ridge National Laboratory (dalevh@ornl.gov)

Keith Kline, Oak Ridge National Laboratory (klinekl@ornl.gov) 
(This page intentionally left blank) 


\section{Table of Contents}

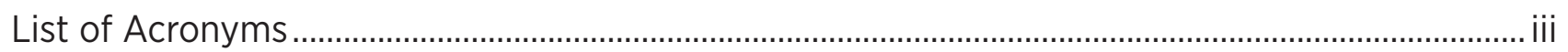

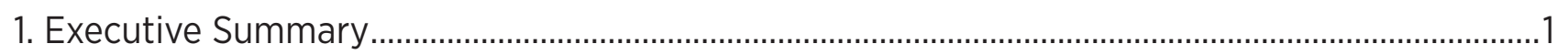

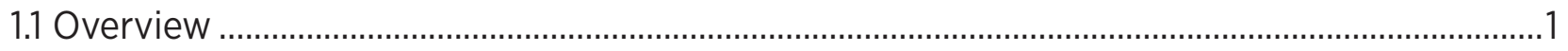

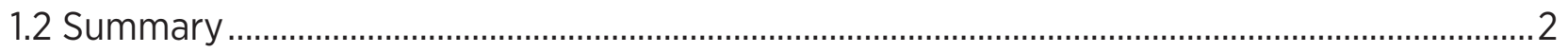

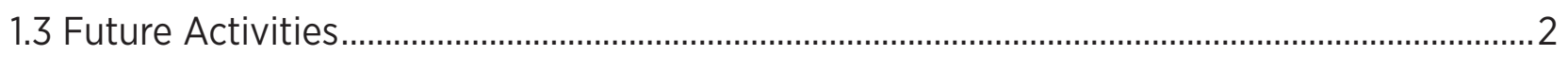

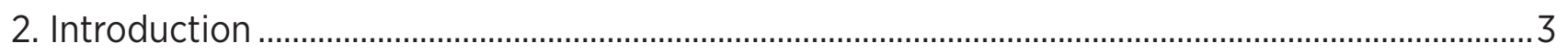

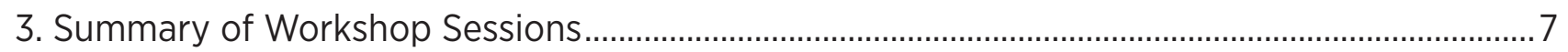

3.1 The Midwestern Landscape ......................................................................................................

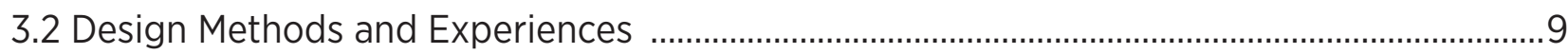

3.3 Assessing Impacts, Benefits, Methods, and Results................................................................ 10

3.4 Policy, Economics, and Societal Interests ……………........................................................... 11

3.5 Certifications, Standards, Guidelines, and International Perspectives .................................. 12

3.6 Workshop Breakouts and Plenary Discussion .......................................................................... 13

3.6.1 Is landscape design the course of action needed to move forward, and if so, how can it be implemented? .................................................................... 14

3.6.2 Are the necessary design and monitoring tools available?

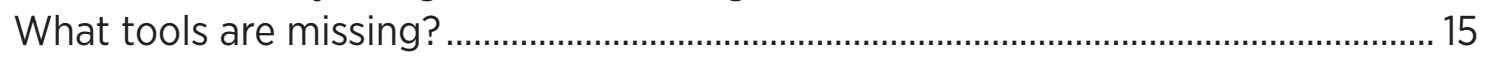

3.6.3 What are the next steps? How can we establish holistic initiatives at watershed or other local scales to demonstrate and promote the benefits of landscape-based bioenergy systems? ...................................................................... 16

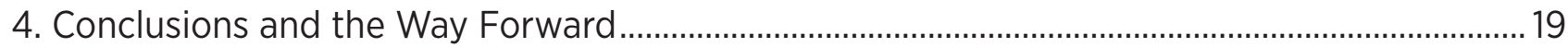

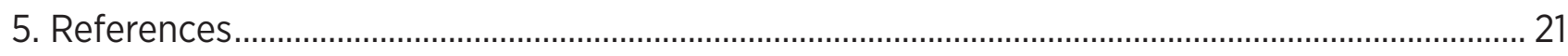

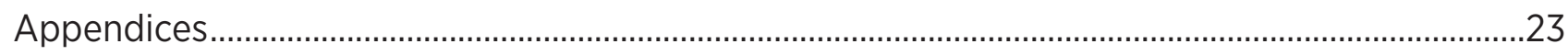

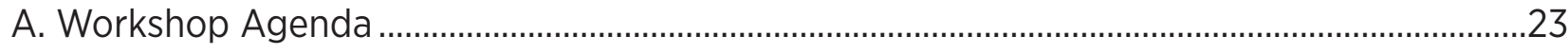

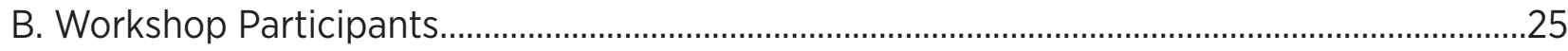

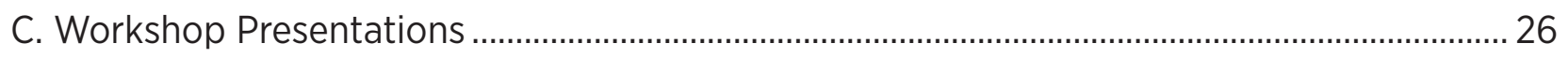

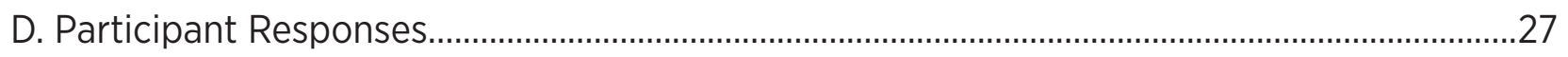


(This page intentionally left blank) 


\title{
List of Acronyms
}

\author{
ARS Agricultural Research Service \\ BCAP Biomass Crop Assistance Program \\ CRP Conservation Reserve Program \\ DOE United States Department of Energy \\ GHG greenhouse gas \\ LEAF Landscape Environmental Assessment Framework \\ REAP Resilient Economic Agricultural Practices \\ RSB Roundtable on Sustainable Materials \\ SWAT Soil and Water Assessment Tool \\ USDA United States Department of Agriculture
}


(This page intentionally left blank) 


\section{Executive Summary}

\subsection{Overview}

Sustainable biomass development is seen as the logical alternative in the medium term to fossil transportation fuels for reducing the nation's dependence on foreign oil and lowering carbon pollution. The Energy Independence and Security Act of 2007 mandates aggressive biofuel production targets for the United States, and this will require deployment of cost-competitive, environmentally sound, and socially acceptable bioenergy sources.

Environmental concerns related to biofuel development, and Midwest agriculture in general, focus primarily on water quality — specifically, nutrient exports that affect both human health (algae blooms) and wildlife habitat. The use of landscape design principles for biomass production has not been thoroughly developed to date, and knowledge is fragmented in scope and among individual projects funded by different entities. People perceive a landscape differently based on their beliefs; thus, deep stakeholder involvement in the planning process is required.

The Bioenergy Technologies Office (BETO) of the U.S. Department of Energy (DOE) focuses on catalyzing research, development, and demonstration of sustainable bioenergy from the feedstock supply, through the conversion, distribution, and end use elements of the supply chain. To this end, BETO established a goal to "identify conditions or conservation practices under which feedstock production scenarios are likely to maintain or improve soil quality, biodiversity, and water quality in major feedstock production regions while meeting projected demands for food, feed, and fiber production" (BETO 2015). In support of this goal, BETO convened two workshops in 2014 to explore the current state of the science, priority research needs, and tools and methodologies for the implementation, demonstration, and monitoring of landscape designs for bioenergy systems across the supply chain and across sustainability metrics.

Desired outcomes from the workshop series included (1) discussion-based assessment of the state of the science in watershed/landscape research and demonstrations, (2) consideration of the issues of bridging scales to provide frameworks for small watershed demonstrations across the supply chain, and (3) identification of example planning tools for landscape placement of bioenergy crops and sustainability analysis.

Workshop One was held in New Bern, North Carolina, on March 3-6, 2014. It focused on bioenergy systems that utilize wood products, provided a framework for considering the application of landscape design for bioenergy, and examined a number of considerations, definitions, and ideas. A report and other materials on this workshop are available on the Bioenergy Knowledge Discovery Framework (KDF). ${ }^{1}$ Workshop Two - the focus of this reporttook place June 24-26, 2014, in Argonne, Illinois. This workshop convened a discussion on the usefulness and feasibility of using landscape management principles to design sustainable bioenergy crop systems in the Midwest. The report, presentations, and agenda are also available on the Bioenergy KDF. ${ }^{2}$

Workshop Two convened experts from throughout the community to discuss questions regarding the current Midwestern landscapes, pressures over land use, bioenergy expectations, and scientific methodologies for design and assessment of landscape design applied to bioenergy and policy, business, and stakeholder participation.

The goal at the conclusion of Workshop Two was to address the following critical questions:

- Is landscape design the course of action needed to move forward, and if so, how can it be implemented?

- Are the necessary design and monitoring tools available? What tools are missing?

- What are the next steps? How can holistic initiatives be established at the watershed scale or other local scales to demonstrate and promote the benefits of landscape-based bioenergy systems?

1 https://bioenergykdf.net/content/incorporating-bioenergy-sustainable-landscape-designs\%E2\%80\%94workshop-one-forestry-landscapes

2 https://bioenergykdf.net/content/incorporating-bioenergy-sustainable-landscape-designs\%E2\%80\%94workshop-two-agricultural-landscapes 


\subsection{Summary}

There was ample support among workshop participants for integrated landscape design, with some disagreement on how well it met everyone's goals. The majority of participants agreed that incentive structures would be more productive in advancing this approach than regulatory mandates.

Obstacles to the implementation of landscape design were also discussed. In addition to a general lack of systemlevel thinking, which causes research, policy, and practices to be stove-piped, participants identified several obstacles related to knowledge, policy, and markets. These obstacles included the following:

- Risks associated with growing bioenergy crops and implementing landscape design. These risks need to be removed or reduced before producers can consider growing bioenergy crops.

- Market availability. Farmers will not grow bioenergy crops if there is no market for the biomass they generate.

- Uncertainty about the scientific underpinnings supporting the value of bioenergy crops. Research should improve the understanding of the value of ecosystem services and the tools for assessing them. Research is also needed on issues of productivity, logistics, and practicality.

- Land ownership issues. As more land is owned by absentee landlords, short rental agreements may prevent the establishment of perennial rotations; however, large-scale management may enable some landscape design practices.

- Lack of incentives to minimize planting and/or fertilizing in areas that are risky or underproductive.

- Biodiversity issues. Unless landscape design could include polycultures, biodiversity will not increase; one monoculture will simply be substituted for another one.

\subsection{Future Activities}

Workshop participants proposed a series of future activities, which included the following:

1. Develop case studies.

2. Address supply chain obstacles.

3. Pursue technical action items such as developing crop integration plans ready for use in the field, developing spatial designs, and increasing the power of research through meta-analysis that fully harnesses existing literature.

4. Promote partnerships to move researchers outside the fence and create communities of growers, academics, researchers, and markets; develop and test long-term contracts to minimize risk; and establish relationships among those who value conservation reserves for wildlife.

Participants agreed that to develop realistic opportunities, the conversation must expand beyond the research environment to the broader stakeholder community. To do that, it is important to begin a process of language harmonization so that the community shares a common set of definitions and goals. This inclusive process of communication and creation of a continuous feedback loop will ultimately deliver solutions that are both achievable and acceptable.

\subsection{Acknowledgments}

The workshop was funded by the U.S. Department of Energy Office of Energy Efficiency and Renewable Energy, Bioenergy Technologies Office (CPS Agreement No. 26645). 


\section{Introduction}

Energy is central to human well-being. Sustainable biomass development is advocated as a logical alternative in the medium term to fossil transportation fuels for reducing the nation's dependence on foreign oil and lowering carbon pollution. The Energy Independence and Security Act of 2007 mandates aggressive biofuel production targets for the United States. The new bioeconomy is based on the deployment of a cost-competitive, environmentally sound, and socially acceptable biofuels, biopower, and bioproducts. The Bioenergy Technologies Office (BETO) of the U.S. Department of Energy (DOE) is focused on catalyzing research, development, and demonstration of sustainable bioenergy from the feedstock supply through the conversion, distribution, and end use elements of the supply chain. As part of its crosscutting support of research in sustainability and strategic analysis, BETO aims to "understand and promote the positive environmental, economic, and social effects and reduce the potential negative impacts of bioenergy production activities" (BETO 2015). Within this aim, BETO established a goal to "identify conditions or conservation practices under which feedstock production scenarios are likely to maintain or improve soil quality, biodiversity, and water quality in major feedstock production regions while meeting projected demands for food, feed, and fiber production" (BETO 2015).

Indeed, increasing the number of demands on the same land resources has prompted researchers to propose radical reframing of the usual food-versus-fuel debate and out-of-the-box thinking, and to call for a holistic reassessment of the way agriculture is now managed to include opportunities offered by novel technology to achieve multiple objectives. For example, grasses could be grown as a bioenergy feedstock as well as a source of animal feed. This approach could be a win-win for the feed production industry (which now uses most of the U.S. agricultural land) and for bioenergy (see Appendix C, no. 19). The increased feed production could free up land for bioenergy. Landscape is not stationary; it is ever-changing. The introduction of soybeans and its use for feed caused a rapid change in the Midwestern landscape in the 1920s. Such a change could happen again. Ensuring that landscapes change "smartly" or planning for a desirable landscape change could be the path to enhance sustainability (see Appendix C, no. 8). Design criteria and rules need to be established to ensure that landscape changes are sustainable (see Appendix C, no. 19).

Landscape design is, in essence, a plan for resource allocation. It is a tool and a science that can be used for developing bioenergy systems that optimize available resources so that multiple benefits are achieved and detriments are minimized. It accomplishes this goal through the study of land use and cover, hydrology, wildlife habitat, agronomy, social systems and behavior, logistics, and economics, and through the design of plausible land use configurations that could meet different given scenarios for bioenergy deployment. Where analytical tools are available for assessing potential impacts of bioenergy deployments, landscape design may allow a focus on alternatives to the critical question, how is bioenergy deployed? Business as usual (where bioenergy crops are deployed similarly to corn and soybeans to maximize profits across large, uniform acreage) is a different modality of deployment than a landscape in which bioenergy crops are grown in buffers, marginal land, right-of-ways, and other land forms. Designing a landscape implies a careful selection of locations, often at the subfield level, in which bioenergy crops could be an alternative to existing grain crops. It allows farmers to improve profits and create ecosystem and environmental services.

The use of landscape design principles for biomass production has not been thoroughly developed to date, and knowledge is fragmented in scope and among individual projects funded by different entities. The objectives of Workshop Two were as follows:

1. To convene a discussion on the usefulness and feasibility of landscape management principles for designing sustainable bioenergy crop systems in the Midwest

2. To develop an understanding of the state of the science, priority research needs, and tools and methodologies for the implementation, demonstration, and monitoring of landscape designs for bioenergy systems across the supply chain and across sustainability metrics. The workshop focused on bioenergy systems in the U.S. Midwestern Corn Belt region. 
Desired outcomes from the workshop included developing a clearer understanding of the state of the science in watershed and landscape research and demonstration, identifying ways to bridgescales from sub-field to larger spatial areas, proposing frameworks for small-watershed demonstrations across the supply chain, and providing examples of planning tools for landscape placement of bioenergy crops and sustainability analysis. Additional outcomes were to reconstruct a kaleidoscope of different experiences across organizations into a plausible "state of the science" and to have a conversation on strategies for engaging communities and the socioeconomic implications for adopters, decision makers, and the public.

Workshop One, the first in the series, was held in New Bern, North Carolina, on March 3-6, 2014. The New Bern workshop, which focused on bioenergy systems that utilize wood products, provided a thought frame around the application of landscape design for bioenergy and a number of considerations, definitions, and ideas.

In Workshop One, participants made three recommendations that must be considered to incorporate landscape design elements into sustainable bioenergy systems:

1. Involvement of stakeholders is critical.

2. Management options need to be studied within a broader context.

3. Attention must be paid to what is doable.

Importantly, though, the New Bern workshop showed that in the case of forestry systems, at least for large, industrial landowners or enterprises, landscape design is already a more concrete reality, because time and land scales associated with woody systems demand long-term planning and coordination. Sustainability elements may further enhance the design, but in essence, long-term planning is already occurring. In contrast, in Midwestern agricultural systems, decisions are made yearly on the allocation of land to crops such as corn and soybeans by individual agents who are constrained by their farm size, economic bottom line, ever-volatile market conditions, and a connection to far-reaching environmental impacts.

People perceive a landscape differently based on their beliefs, and this central notion guides the need for deep stakeholder involvement in the process. By definition, landscape design must integrate different land uses and objectives and, in this case, consider bioenergy as an opportunity for designing landscapes that add value to the ecosystem (see Appendix C, no. 2). Landscape design takes context, trends, and current site conditions into consideration. Negative impacts at the landscape-planning level can be avoided by conserving priority ecosystems and social services, considering the local context, and adapting plans over time based on monitoring results. In a well-designed landscape, there should be no waste of land, inputs, or resources. Pressures and incentives for landscape design include legal demands or regulations, customer requirements or specifications, stakeholder concerns about competitive advantage, and the demands of social groups. Obstacles to design implementation are landowner rights, as well as the presence of well-established traditional practices, the need for upfront planning, the complexity of coordination in executing the design, and higher initial costs.

To begin gathering a more complete picture of what has been done, by whom, and with what results that could be applicable to the design of sustainable bioenergy landscapes in the Midwest, Workshop Two was designed to convene experts that could discuss the following questions:

- How was the Midwest landscape formed; what represents this landscape now; what are the pressures over land use in this region; and what bioenergy resources are expected from it?

- What design methods and experiences are currently available?

- What are the methodologies for assessing impacts and benefits?

- What are the policy, economics, and societal interests?

- What is the level of buy-in across the supply chain?

- What are the international perspectives and certification issues? 
Ultimately, the workshop aimed at a collective discussion of the following questions:

- Is landscape design the course of action needed to move forward, and if so, how can it be implemented?

- Are the necessary design and monitoring tools available? What is missing?

- What are the next steps? How can holistic initiatives be established at watershed or other local scales to demonstrate and promote the benefits of landscape-based bioenergy systems? 
(This page intentionally left blank) 


\section{Summary of Workshop Sessions}

\subsection{The Midwestern Landscape}

The geology of the Midwest landscape was created by the Laurentide ice sheets 10,000 years ago. More recently, it was influenced by anthropogenic forces: what would have been an oak-hickory forest was maintained by Native Americans as a prairie for sustaining bison and thus, managed for grazing. Tall, mixed, and short grasses dominated the prairie depending on soil fertility and water availability. Abundant swamp and marsh areas limited agriculture until drainage and steel plows turned them into cultivated land. These grasses produced high organic matter reserves in the soil from their extensive and deep rooting. Grassland produced much more biomass on an annual basis than forest vegetation. The wet soil conditions through much of the year also helped to maintain the accumulated soil organic matter. The grass roots also helped release larger amounts of nutrients from the soil minerals. Those nutrients were taken up by the grass roots and left by the plant residue to accumulate in the upper soil horizons over thousands of years.

This managed rangeland and prairie ecosystem, prevalent until the mid-1800s, was replaced by forage and grain crops as the European settlers moved into the region. Corn, small grain, and forage rotations were predominant until the 1960s, when declining livestock and increasing cash grain markets led to a shift to mostly corn and soybeans. This land is ideal row-crop farmland, with flat topography and fertile soils left by the prairie system.

Drainage continues to be an issue. Dutch and German immigrants created underground tile drainage and surface ditch systems, making Midwest soils most suitable for intensive agriculture. Today, these ditches are at the heart of environmental issues because they carry high loads of nitrogen, phosphorus, and water to surface streams and lakes.

In much of the major U.S. corn and soybean production area, the farmers own a relatively small percentage of the land that they manage. In some central Illinois counties, only about $13 \%$ is owned by the farmer; in north-central Iowa, less than $40 \%$ is owned. Much of the ownership is in the hands of family members or families who previously farmed the land, but outside investors are also important owners. ${ }^{3}$ Environmental issues such as water quality, production costs, increasing land costs, and concerns over the increasing cost of inputs determine choices on land use. While yields continue to increase, the current cost of production is $\$ 3.94$ per bushel of corn and $\$ 10$ per bushel of soybeans-levels that are higher than the current trading prices. ${ }^{4}$ While the dominance of corn and soybeans is expected to continue in the future, improved conservation is increasingly of interest, driven in part by grower initiatives, conservation ethics, and external pressures, as well as potential for increased efficiency and profit. Self-interest drives farmers' choices of alternatives such as forages, vegetables, and bioenergy crops. Ecosystems services markets are viewed with interest. Any changes in cropping systems must first be proven to be positive to the farm operators' financial bottom line if they are to be adopted. New crops must first be proven to have dependable markets before a change in crop choice will occur (see Appendix C, no. 3).

Production of corn and corn residues is increasing due to both production efficiencies and expansions in acreage (USDA ERS 2011, see Appendix C, no. 4). Other biomass feedstocks such as dedicated bioenergy crops are in much shorter supply. DOE, the U.S. Environmental Protection Agency (EPA), and the U.S. Department of Agriculture (USDA) have three separate visions for what the resource base might be expected in the future; however, all three agencies agree that corn will provide the most important resource base and that the Midwest will play a large role in this production. The combination of soils and climate in the Midwest makes corn and soybeans the best crop choices for the majority of the region. Moreover, the infrastructure for production-input supplies, transportation, and markets for corn and soybeans-is already in place. If anything, the advantage of the soilclimate combination and current infrastructure must be fully utilized in coming years as demand for these crops increases (see Appendix C, no. 4).

\footnotetext{
3 http://www.agcensus.usda.gov/Publications/2012/Online_Resources/Ag_Atlas_Maps/Operators/Tenure/12-M116-RGBChor-largetext.pdf

4 Based on http://www.farmdoc.illinois.edu/manage/2015_crop_budgets.pdf
} 
There is less consensus among the three analyses on the role of other bioenergy crops. USDA and EPA project a larger role for perennial grasses than DOE, and the three analyses differ on the role of other crop residues, woody residues, and annual energy crops (Keeler et al. 2013, see Appendix C, no. 4). From the supply side, issues are present in the narrow gap between the willingness to pay and the willingness to accept. Non-stover or residue crop availability will depend on price support mechanisms, including crop insurance, which is important for addressing farmer risk. On the demand side, while the cellulosic industry is still being established, available resources are underutilized. There is a need for expanding biomass markets for electricity and heat and for ecosystems services provided by growing the biomass. As corn grain production increases, the production of corn stover biomass will also increase, and the possibility of making a higher percentage of that stover available for other uses, such as bioenergy, is expected to become more acceptable (see Appendix C, no. 4)

Environmental concerns related to biofuel development and Midwest agriculture, in general, focus primarily on water quality, specifically, nutrient exports that affect both human health (algae blooms) and wildlife habitat. Environmental and economic impacts are of concern at the local and regional levels. The National Rivers and Streams Assessment (NRSA) found that in the Midwest, 54\% of stream length was either in poor or fair condition relative to total phosphorus, and 71\% was in poor or fair conditions for total nitrogen concentrations (EPA 2013, see Appendix C, no. 5). The Gulf of Mexico's Hypoxic Zone is due in large part to nutrient inputs from over fertilization (66\% and 47\% for nitrogen and phosphorus, respectively) and livestock operations (37\% and 5\%, respectively). Decreases in nitrate in the Iowa and Illinois Rivers during the 2000-2010 time period were overshadowed by increases in the upper Mississippi and Missouri Rivers. Much of the nitrate entering the Mississippi River comes initially from tile drains. Tile drainage has increased substantially recently; it is estimated to be as high as $50 \%$ in cropland (Ohio and Indiana), although there is no effective way to assess the extent and location of the deployed tile drainage system (Jaynes and James 2008, see Appendix C, no. 5). Many of the tile and surface drains were built in the late 1800s, and there are no good records of their location. Over the past 20 years, many newer, more efficient systems have been installed to remove water even more quickly and completely. Recent technology that can manage the tile systems (e.g., turn off and on remotely) offers potential to help regulate water and nutrient losses from the field, but these systems are not yet widely implemented.

Conversion of native ecosystems to agricultural land at the rate of $1-5 \%$ per year in the western Corn Belt has also been a concern for wildlife habitat. Rapid population declines of grassland bird species due to habitat loss have been observed. Conversion to agricultural use has also drained some $40-90 \%$ of native wetlands in the Prairie Pothole Region, with impacts on both breeding and wintering habitat and decreased flood mitigation and buffering capacity (see Appendix C, no. 5).

One possible solution to decreasing the rate of conversion of native ecosystems is to intensify production of crops from existing agricultural lands. Landscape design allocates land resources such that the desired production occurs in an organized way across the area. There is a sizeable interest in using marginal land for bioenergy expansion; however, a precise definition of "marginal land" remains elusive. The rationale for this interest is that marginal land - perhaps better defined as having limited efficiency for feed or food crops (Werling 2013, see Appendix C, no. 6) - may be more suitable for sustainable production of bioenergy perennials. In brief, marginal land has been defined as land unsuitable for food production, lower quality, or economically unsustainable (Shortall 2013, see Appendix C, no. 6). Land could be considered marginal because of small field size or irregular shape, shallow or infertile soils, high erosion, poor drainage, and/or lack of water. Production-based definitions include land with corn yields at least $25 \%$ less than the county-wide average. Farmers do not need definitions to help them identify marginal lands; they know precisely what land is marginal for them. Often this land presents farmers with a conundrum: it will likely not produce a successful crop, but farming these lands provides for crop insurance, thus delivering financial security while causing environmental losses.

Clearly other markets need to be found, because the best environmental option may not pay the bills for the farmer, and the best economic option may be at the expense of the environment. One solution could be to place higher value on the ecosystems benefits of perennials, such as switchgrass than on annual crops. For example, switchgrass grown on marginal land has shown to be net energy positive (Schmer et al. 2008; Werling 2013, see Appendix C, no. 6) and to store elevated rates of soil organic carbon within its deep roots (Follett et al. 2012, see Appendix C, no. 6). Large land areas, such as pivot corners, are available for perennial grasses even in the most intensively managed regions. New cultivars will optimize returns on marginal land and thus increase awareness of its value. 
While research on and awareness of marginal land is increasing, researchers need to better define marginality in their work by seeking farmer input on their reasoning for the areas that they do not farm within their lands. Market creation will be essential in providing farmers with economically viable options. Also, policy attention to the disparities within crop insurance is needed to provide some level of security to the producer. It would be important to change farmer's attitude towards farming marginal lands to receive a guaranteed payment from crop insurance.

Farming perennials is not a huge cultural shift for famers, who are not averse to growing them; the problem is in establishing markets. In addition, to allay concerns over introducing another monoculture, research on polycultures is continuing and guidelines have been developed to protect wildlife habitat for specific areas such as the Prairie Pothole region (see Section 3.5).

\subsection{Design Methods and Experiences}

Holistic planning is the basis of landscape design principles. Through holistic planning, environmental and socioeconomic sustainability for a multipurpose landscape can be envisioned. For example, resource recovery principles can be applied to recover nutrients lost from grain crops to boost the production of bioenergy crops. The spatial arrangement of crops must be suitable and well designed at a scale often larger than a single field, but with a granularity that captures variations at the subfield scale. When implementable landscapes are being planned, designing at the watershed or subwatershed scale is important because this is the scale at which farmers introduce new practices, and outcomes are easier to measure. Design elements need to be selected based on an initial and thorough understanding of the priorities of specific objectives and should include site, scale, soils, and crop properties as tools so specific engineering functions can be applied to meet land use outcomes. Soil types, vulnerability to environmental insults, yield potential, rooting depth, yields, water use, and growth conditions are a few important determinants in the pairing of crops with soils and their land allocation. Through an iterative process, the best designs can be selected to deliver specific objectives and then mediate across multiple objectives. Iteratively scaling from landscape to field and vice versa allows impacts to be assessed and targeted solutions to be designed (see Appendix C, no. 10).

Alternative future scenarios that embody different trajectories of landscape change and result in different future landscape patterns can be employed to help decision makers consider innovative possible futures and anticipate the implications of landscape change (Nassauer and Corry 2004, see Appendix C, no. 11). Alternative future scenarios that employ visualizations of future landscape patterns can be particularly effective tools for enhancing communication among different disciplines and stakeholders by gathering them around the evaluation of a common visible object and harmonizing different underlying assumptions and perceptions about a phenomenon. Stakeholder participation in development of alternative future scenarios or future landscape patterns can enhance their relevance. Stakeholder participation in assessment of future landscape patterns is essential to making these patterns actionable (Nassauer et al. 2004).

Landscape designers provide normative (not predictive) alternative designs that reflect specific scenarios. A normative process describes what should be rather than what is likely to be or could be (Evans et al. 2006). Knowing that all these alternatives are plausible allows identification of the best alternative from a policymaking perspective. Linking scenarios of plausible futures to physical models allows detailed prediction of the impacts of specific designs at larger scales, such as a watershed. An example of this process applied to a small watershed in Iowa is found in Nassauer, Santelmann, and Scavia (2007).

To assess the physical impacts of a particular landscape change, modeling tools can be developed to examine impacts on water quality, carbon accruals, soil quality, nutrient removal, or other indicators. The USDA Agricultural Research Service (ARS) Resilient Economic Agricultural Practices (REAP) program utilized multiple technologies to collect 239 site-years of stover harvest data showing the importance of a landscape vision for soil quality in planning for sustainable stover removal. This importance was underlined by the variability associated with different soils, weather patterns, and crop growth conditions (see Appendix C, no. 12) This variability can be assessed by using tools such as the Landscape Environmental Assessment Framework, a modeling suite that analyzes management techniques at the subfield level. Based on this type of analysis, different rotations and landscape management techniques can be developed and proposed that offer many opportunities for including bioenergy crops, as well as stover removal. This more flexible landscape management is critical for providing market pulls and a diversified 
supply chain. Starting with the economics, the Landscape Environmental Assessment Framework tool can map the parts within a field that are profitable and those that are not. This mapping has tremendous implications for insurance policy and decisions, such as developing insurance strategies based on granular productive capacity and rate of return. When standard deviations on average profits are large, a pre-set acceptable loss could be defined and farmers could determine which parts of a field could either not be cultivated or be dedicated to alternative crops with lower inputs, thus reducing the risk profile (see Appendix C, no. 13).

In general, there is a detectable increase in the dialogue on landscape design for bioenergy systems in recent times, and this brings into focus a possible interest or way forward. A convergence of developments may be at the base of this increased dialogue: the realization that resources need to be optimized to deliver ever more goods and services from the same base, and the formulation of potential alternative markets (such as that of feed) for the valorization of a multi-use resource such as stover. Critical to the further advancement of this path is the involvement of multiple stakeholders. It is important at this point to initiate a communication effort, including media and banks, starting with the fundamental economics in farmer decisions in lease agreements, crop insurance, and lending arrangements. It is also important to motivate landowners and operators and to find ways to develop this motivation. Developing integrated landscape systems could encourage the formation of specific enterprises servicing the bioeconomy industry (e.g., specialized machinery operations, off-season harvest, storage, transport, processing, know-how, certification).

\subsection{Assessing Impacts, Benefits, Methods, and Results}

Assessing the impacts of specific landscape designs on water quality, biodiversity, logistics, and other environmental indicators can leverage tools derived from other germane fields of study, such as conservation. While models are tools that can aid in watershed work, they should be used with caution-some analyses (hydrology) are better modeled than others (nutrient loads) (Osmond et al. 2012, see Appendix C, no. 14). One of the best examples of assessing conservation effects on water quality is provided by the experiences of the USDA Conservation Effectiveness Assessment Program (CEAP). Terrain analysis targets vulnerable areas on the landscape, such as erosive land (Baffaut, 2013, see Appendix C, no. 14), and identifies placement sites for perennials (regardless of their use for bioenergy) to control runoff. However, scale of problems and scale of solutions are not always the same, and it is difficult to transition from a given scale to a lower or higher one. Documenting water quality benefits is complicated because of spatial and temporal scales. Few studies have quantified the effects of individual conservation practices on water quality over five years (Tomer and Locke 2011, see Appendix C, no. 14). The disproportionality hypothesis suggests, however, that spatial placement of best practices is critical. Because we are considering relatively small areas of fields, scattered throughout the watershed, scale becomes a serious issue. The solution may have a major impact on the subfield involved, but may have relatively little impact on the whole watershed, until considered in the aggregate. It still may be beneficial overall.

Humans predominate in landscape changes, often to the detriment of biodiversity. The design of agricultural landscapes can be informed by knowledge of how land cover and land use affect biodiversity and, in turn, how these crop species deliver vital ecosystem services to the agricultural landscape (see Appendix C, no. 15). As an example, landscape context affects the potential for biological pest control (Werling et al. 2011), whereas perennial crops are expected to decrease pesticide application on the landscape (Meehan et al., 2011). Moreover, economic valuations of biodiversity-related ecosystem services can allow for a more holistic accounting of trade-offs in bioenergy landscapes, in a way that is spatially informed-keystone hectares could be identified where the trade-offs can be managed (see Appendix C, no. 15).

Practical approaches to measuring the impacts of alternative landscapes include field techniques as well as modeling. Plot-scale data have several limitations in adequately representing specific processes in models at higher scales, one of which is the interaction between plant genotypes in the environment and management options. Another important aspect that needs to be captured is the interdependency of specific landscape elements, of which the most critical element is water and nutrient transport. Targeted information can be provided by specialized field settings such as lysimeter plots, in which exports of nutrients and other chemicals are assessed (see Appendix C, no. 16) and used as parameters in models such as the Soil and Water Assessment Tool (SWAT). However, key data linked to detailed metadata would provide much better representation of cropping systems in current models and provide evidence-based practice guidance (see Appendix C, no. 16). Cross-validation using different models, and 
collaborations with existing commercial deployers of biomass, could provide dramatic opportunities for upscaling and also increase the level of confidence in predictions.

Another important design need is that of connecting integrated landscape management with feedstock logistics to deliver cost-effective and practical designs. The Advanced Uniform Design (AUD) promoted by DOE could support the transition from a low diversity, large-volume-per-area biomass supply from a conventional crop management system, to a logistically complex, integrated landscape management system in which high-diversity feedstock is produced at low volumes in scattered parts of the landscape. Preprocessing facilities distributed on the landscape (depots) are the core of AUD; these can process smaller quantities of specific biomass types to provide a uniform, reliable, and densified version for shipping economically to a more distant biorefinery, either as is or preprocessed for particular conversion requirements. The Biomass Logistics Model developed by the Idaho National Laboratory (INL) allows for the design of feedstock supply systems and can be adapted to fit the case of distributed, diversified biomass grown in small-scale amounts across the landscape (see Appendix C, no. 17).

Air quality impacts are examined by using a $2 \times 2$ matrix (models, measurements versus concentrations, emissions $^{5}$. Establishing a baseline for reference and developing clear research questions, methods, and metrics are keys to a correct evaluation. In particular, it is important to ensure that study methods are appropriate to associate estimated changes in that particular metric with specific sources. Research needs in relation to air quality include open access data, education, and a more focused effort by researchers to discern source contribution to emissions and concentrations.

\subsection{Policy, Economics, and Societal Interests}

While the main drivers for expanding bioenergy include replacing imported oil and managing climate change, the policy environment is very fragmented and piecemeal. In general, risk aversion and profit maximization create a preference for existing commodity markets and policies. Crop insurance is a major policy factor in maintaining current rotations because bioenergy crops are not covered by crop insurance subsidies (see Appendix C, no. 20).

Several policy elements are of interest for landscape design. The 2014 Farm Bill includes a provision that allows for crop insurance premium subsidies to be withheld in case of noncompliance with conservation provisions. This implies that vulnerable land could become ineligible for commodity programs and crop insurance subsidies, so producers could become more interested in converting to different rotations or land covers such as bioenergy crops. The Farm Bill Energy title includes the Biomass Crop Assistance Program (BCAP, www.fsa.usda.gov/bcap), which supports the establishment and production of eligible crops for bioenergy, and assists landowners and operators with the collection, harvest, storage, and transportation of eligible material for use in biomass conversion facilities as well as research. Currently, BCAP has enrolled 11 project areas with 48,000 acres, and its annual rate of expansion could be as high as 15,000 acres. It provides matching payments for feedstock provided to the conversion facility, caps establishment costs for perennial crops, contains provisions to use BCAP funds for technical assistance, and allows expiring CRP acreage to participate in the program (Novak 2014). BCAP, however, does not have specific mechanisms for selecting land for enrollment or tools for addressing price and yield risks, and it has little flexibility on cost share caps on establishment costs; this is a problem for bioenergy crops whose establishment is expensive. One solution could be to supplement BCAP with a crop insurance program and establish loans for energy crops (see Appendix C, no. 20).

Combined funding for the Environmental Quality Incentives Program and Conservation Stewardship Program is projected to account for more than $50 \%$ of conservation spending in the next few years and could be of interest for establishing bioenergy crops. Conversely, the uncertainty around the Renewable Fuel Standard (RFS2) mandates is not creating a supportive environment for entrepreneurs. Another policy instrument of interest is the Clean Power Plan Rule (partly struck down by the Supreme Court's Clean Air Act Decision of June 2014), which includes reducing emissions by substituting generation with low- or zero-carbon generation, and California's AB32 and the Regional Greenhouse Gas Initiative, which allow for sequestration of carbon in forest projects. Private-public partnerships are better at valuing multiple ecosystem services at the same time; however, they present problems related to spatial targeting (because they may leave some farmers ineligible to participate) and to the quantification and monetization of ecosystems services (Jenkins, Murray et al. 2010, see Appendix C, no. 20).

5 http://www.esrl.noaa.gov/csd/groups/csd7/measurements/2011biocorn/ 
Economic sustainability and ecosystems services are tightly linked. Simulation and modeling tools, including decision-making frameworks, can help in evaluating and addressing multidimensional payoffs (see Appendix C, no. 22). These decision tools can be linked with other modeling resources to connect to physical measures of desired outcomes such as yields, income, or ecosystem services. Together with stakeholder-driven designs, these tools can help with strategic decisions such as determining whether it is better to plant switchgrass where soil organic carbon is high to prevent degradation or to planting it where it is low to increase it. The process of embedding sustainability within place-based deployment is the base of the LandLabs initiative (Jordan 2013).

Conservation and environmental groups are an important reference point for directing and developing integrated landscapes. For example, The Nature Conservancy has been moving from its interest in conserving "untouched land" to focusing on addressing existing practices, including agricultural practices. It has undertaken a series of proof-of-concept watershed projects in the Upper Mississippi River Basin (the Great Rivers Partnership) where it supports precision conservation to preserve biodiversity and water quality. Using the Wisconsin Phosphorus Index to estimate annual phosphorus delivery in runoff from each field, the Nature Conservancy found that phosphorus was mostly delivered by fields, not barnyards. Also, landscape interventions such as contour strips, cover crops, grassy filters, and nutrient management were much cheaper than practices targeting barnyards and feedlots. Assessments in these studies were made using a sustainability calculator (www.fieldtomarket.org/fieldprintcalculator/). Following an evaluation of the economic and ecological impacts of bioenergy opportunities in Minnesota and Wisconsin, the Nature Conservancy has determined that although numerous great habitats were created, markets are still not supporting bioenergy; therefore, for now, bioenergy is not part of its strategy. The concept of integrated landscapes; however, is central to its approach, and the Nature Conservancy supports the use of more perennial cover, which reduces sediment and nutrients in freshwater and creates habitat (see Appendix C, no. 23).

\subsection{Certifications, Standards, Guidelines, and International Perspectives}

Integrated bioenergy landscapes are predicated on the need to produce sustainable bioenergy. What constitutes sustainable bioenergy is determined by regulations and standards, and certification schemes allow producers (or other stakeholders) to prove that the bioenergy produced is indeed sustainable. Further, depending on the certification process, there may be linkages between the assessment of sustainability indicators and the valuation and trading of ecosystems services.

The interest in sustainable bioenergy is global. Brazil has six main biomes (a region characterized by dominant forms of plant life and prevailing climate), and its largest biofuel crop is sugarcane. Most sugarcane is grown in the Cerrado, a savanna-like biome. Because it needs a dry period to mature, sugarcane is not suitable for Amazonia. Of Brazil's total emissions, $80 \%$ comes from land use change, deforestation, and agriculture. Brazil is trying to reduce these emissions by 2020, following the Copenhagen Agreement, by reducing deforestation and fires, lowering greenhouse gas (GHG) emissions in steel and iron industries, and developing low-carbon agriculture for the main crops (i.e., corn, soy and sugarcane). To reduce GHGs, Brazil is decreasing deforestation and stimulating the recovery of degraded areas. Brazil has just begun planning landscape design concepts in the sugarcane-based ethanol production system, and already some governmental initiatives are present. Although sugarcane has good potential for landscape integration, there are obstacles to integrated landscape design in Brazil: land tenure is often unclear, the legal process is slow, and the drivers for change are not well understood. Other barriers are not found in recent regulations, but rather, in technology, finance, and information dissemination. Certification is geared to best practices and centers around access to markets in the Bonsucro standards (see Appendix C, no. 27). ${ }^{6}$

Agriculture in the United States is unaccustomed to certification. Biofuels systems have started to develop certification approaches because they have suffered from a perception of poor sustainability. Current regulations set by the U.S. Environmental Protection Agency, and in California and Europe, demand sustainability in biofuel production. In certification, it is imperative to avoid silos and develop a "systems approach to standards." Several standards are in existence such as the Biomass Access Standards Group and the Roundtable on Sustainable Materials (RSB). Standards rely on institutional architectures and translate to holistic policy decisions by finding stakeholder alignment. Standards can be used together with scientific capacity to show the benefits of integrated landscape designs, even at the subfield level. The focus must be on collecting data that validate the standard. Information outreach is also important; a good example is available at the Explore Shale website (see Appendix C, no. 28). ${ }^{7}$

6 http://www.bonsucro.com/

7 www.exploreShale.org 
The RSB began in 2007 at the Swiss Federal Institute of Technology and has since built an international presence. ${ }^{8}$ The RSB certification process is a feedback cycle between a business and a standards committee. RSB's work is largely based on verification of practices (not metrics or outcomes), but it did benchmark the Bonsucro standards. Issues of sustainability are driven by policy and also make their way to the public. In instances of public pressure and regulation, the private sector responds. For example, airlines are subject to ETS (European legislation): they are taxed on carbon and want to be certified as sustainable. Advanced biofuels have unique risks and opportunities. Certified biofuel plants include carinata, camelina, jatropha, sugarcane, quick coppicing poplar, and various wastes and residues. Identifying a mechanism to integrate landscape design principles into sustainability certification would be a desirable achievement (see Appendix C, no. 29).

Certification affects landscape design in several ways:

- It provides a base of indicators and methodologies that could be used in developing metrics for sustainable landscapes.

- It provides a base for conducting multivariate analyses, which always involve the human element.

- It has the potential to link practices vetted by multiple stakeholders to new markets.

It is important to develop certification before systems become commoditized; commoditized agriculture resists certification because it is perceived as inefficient.

To help guide biomass production practices that consider the needs of wildlife, the National Wildlife Federation (NWF) supported development of Best Management Guidelines (BMGs) relevant to perennial herbaceous biomass in the Northern Great Plains. There are numerous existing BMGs on forestry, but not on agriculture, and especially not on perennials. Hence the NWF has narrowed its focus to the Prairie Pothole Region and grasses including switchgrass.

NWF believes that biomass "done right" has the potential to address global warming, provide ecosystems services, and be economically advantageous. The Prairie Pothole Region has significant potential for biomass production and a significant importance for wildlife and pollinators. The $30 \mathrm{BMGs}^{\mathrm{B}}$ developed by the $\mathrm{NWF}^{9}$ (are useful examples of target practices to consider in integrated landscape design. As an example of BMG, late harvesting of crops with no-till management is recommended because it leaves the ground cover for birds to use. Among the guidelines relevant to landscape design is the recommendation to not convert rare native ecosystems but limit biomass to marginal land, match planting with conservation, correctly time harvesting to provide cover for wildlife, and emphasize polycultures over monoculture (see Appendix C, no. 30).

\subsection{Workshop Breakouts and Plenary Discussion}

A panel of scientists, farmers, industry representatives, and local stakeholders discussed issues surrounding the buy-in on bioenergy landscape design across the supply chain. The consensus among panelists was that the current lack of a viable market is the major impediment to the penetration of bioenergy, and that multiple market opportunities at a small scale would result in a diversified landscape and could be the precursors and enablers of a broader market serving a future biorefinery.

Opportunities for biomass to compete with liquid propane gas were highlighted. Most rural communities and farms are off the natural gas grid, and self-sufficiency from propane could be a strong motivator to enter the bioenergy crop arena if the technology to use biomass in specialized burner systems was available. A half-acre of miscanthus is required to heat an average farm home. There is no U.S. industry that uses bioenergy crops for residential heating, whereas European technology is available to effectively use miscanthus for heating. This technology, however, is not available in U.S. markets. A size guideline should be developed so that there are no air quality permitting requirements.

8 www.rsb.org

9 http://www.nwf.org/ /media/PDFs/Wildlife/BiomassBMGPPR.pdf 
Also related to markets and end uses is the possibility of pelletizing stover for feed as well as for bioenergy. This approach was received favorably by panelists, although previous industry projects such as the DAM (Dow, Archer Midland and Monsanto) project have highlighted its costs. While stover was considered the low-hanging fruit, caveats were expressed about the need for understanding issues of soil fertility due to stover removal. Issues with maintaining fertility also encompass trusting current analytical methods to carefully reflect soil conditions.

The consensus was that landscape design should consider issues of logistics, biodiversity, and economics. Information on technical and economic aspects should be disseminated to agronomists and farmer consultants, who have producers' trust and are able to watch the fields continuously. Farmers are interested in doing the right thing, so it is better to inform and guide them than to regulate them. The effect of ownership structures on decisions needs to be understood. It is increasingly the land operator who decides what to grow and how; ultimately, however, it is the final drivers that will make the difference. Landowners usually do care about maintaining soil fertility, so soil quality should be rewarded in the long term with decisions based on soil quality. be rewarded long term with decisions based on soil quality. One concern from the logistics standpoint is that a subfield diversified landscape may go against the current trend in which farmers seek to increase efficiency by using increasingly large machinery and aggregating small fields into large ones. Precision agriculture tools, however, may help to devise landscape-level management decisions.

Industry is interested in markets and materials that are cost effective at specific scales. Quality and stability under storage are also important factors in determining market potentials. Logistics is key to maintaining stable, quality biomass.

\subsubsection{Is landscape design the course of action needed to move forward, and if so, how can it be implemented?}

\subsubsection{Support of implementing Landscape Design}

There was ample support among workshop participants for integrated landscape design, with some disagreement on how it could meet everyone's goals. There was also a general agreement that incentive structures would be more productive than regulatory activities in advancing this approach. Workshop participants offered several reasons for supporting integrated landscape design.

First, from a societal perspective, there is a need to optimize system performance. Producing more out of the same resources can be achieved only through optimization of the resources available. To achieve better system performance, the management toolbox available for managers to deal with complex systems needs to be augmented. Landscape design can help with both the planning and the monitoring of impacts. While conventional agriculture responds to only one objective - profit, there is now a demand to meet more objectives, and management options for doing so are required. The most important objective, in addition to profit, is the provisioning of ecosystems services. Ecosystems services were considered an opportunity or even an enabler to increase and support productivity and income and to provide a framework for evaluation. Overall, it was deemed a strong possibility for positive outcomes that deserved policy consideration. From a governmental policy perspective, landscape design could also provide an opportunity to achieve better returns from federal incentives, if it could avoid, for example, planting unprofitable commodities on land that is risky because there is crop insurance.

Second, some level of landscape design is already occurring through farm management; thus a more organized approach could provide a framework for systematizing management options and finding an economically profitable design that improves environmental performance, targets conservation practices, and identifies crops to match technology (switchgrass, willow). If producers could be informed on subfield returns, new management toolkits should help increase productivity, especially per-unit input.

Finally, from a producer's perspective, a diversified landscape is an opportunity to reward producers while correcting false economies which do not account for externalities. Producers respond to profits; bioenergy could provide an economic counterincentive to monoculture and establish a diversified rural economy. 


\subsubsection{Obstacles to the Implementation of Landscape Design}

Obstacles to the implementation of landscape design were also discussed but not ranked. In addition to a general lack of system-level thinking, which causes research, policy, and practices to be stove-piped, several obstacles related to knowledge, policy, and markets were identified.

There are risks in growing bioenergy crops and implementing landscape design that need to be removed or reduced before producers may consider planting bioenergy crops. Partnerships with state and local entities could support these activities better than top-down regulations. The lack of an equal playing ground for crop insurance was a major theme often discussed during the workshop. Bioenergy crops do not offer the same protection from a crop insurance subsidy standpoint as commodity crops. An obstacle in developing crop insurance policies for bioenergy crops is that risk management requires more data on performance and productivity of bioenergy crops in agricultural lands, which is currently limited. Even rarer are data on performance and productivity in marginal land.

Market availability is another obstacle to implementation. Farmers will not try to integrate their landscape with bioenergy crops if there is no market for biomass. Also, crop insurance for bioenergy crops will not be available if there is no market.

Insufficient scientific underpinnings or insufficient coalescence of the science around objectives, outcomes, and data is another obstacle. How does landscape design influence water quality? For example, it is not yet known how to measure and develop decision tools. Collection and analysis of samples are expensive. This lack of information needs to be addressed and then turned into educational efforts. Water quality trading, for example, could be an opportunity to incentivize this activity; however, there should be science supporting this concept. Research should improve understanding of the value of ecosystem services and improve the tools for assessing them, as well as provide a framework for placing the opportunity in context. Developing a precedent, such as a case study or demonstration, should be a priority to show how this approach can work and what results it can deliver.

Technical obstacles were also discussed. Because commodity crops rely on increasingly larger machinery for field operations, operating at a subfield level and with irregular contouring may be considered an inefficiency. Also, drainage systems may be in conflict with landscape design as they short-circuit the opportunity to recover nutrients and water. Again, data concerning issues of productivity, logistics, and practicality need to be collected and summarized.

Cultural reasons and lack of education on the subject may also prevent farmers from adopting alternative farm designs. Respect for tradition, risk aversion, reputation loss, and neighbor-to-neighbor perception are important to farmers. A well-tilled field is respectable and shows good farming skills ("mow your ditches!"), while alternative landscapes may appear untidy or otherwise unacceptable by the community.

Land ownership may be another obstacle; as more land is owned by absentee landlords, short-term rental agreements may prevent the establishment of perennial rotations. However, large-scale management may enable some landscape design practices.

Other concerns were the lack of incentives to avoid planting and/or fertilizing in areas that are risky or underproductive and the concern that unless landscape design could include polycultures, it would not result in an improvement in biodiversity because one monoculture would be substituted with another one.

\subsubsection{Are the necessary design and monitoring tools available? What tools are missing?}

Breakout groups discussed the sustainability indicators that can be designed for and what tools are available for designing and monitoring integrated landscapes. One important realization during the discussion was that there was little uniformity in meanings attributed to different words across the large variety of workshop participants. It is important that definitions are agreed upon; what is an indicator, a metric, and so forth? These terms need to be defined and stated when different stakeholders come to the discussion table with their different backgrounds. A common general opinion was that "hard science" is ahead of "soft science" (physical science ahead of social science); however, that belief may be biased by the prevalent background of workshop participants. 
The choice of sustainability indicators needs to be driven by project objectives (i.e., maximize biomass yields; maximize soil carbon; minimize GHGs or water impacts). There is a broad range of heterogeneity in indicators, which is mostly derived from scale issues. Field, watershed, state, and regional scales use and need different indicators and tools. Analytical tools are required to aggregate data across different study fields and scales.

For some (or many) indicators - for example, GHGs and soil carbon - there are abundant methods of analysis but a shortage of monitoring and long-term data. For water quality, indicators are well-developed, but tools for assessment need improvement. Soil quality is another important indicator for which tools are improving, including testing for carbon and phosphorus, especially with stover removal. Concerns over potassium drifting lower in soils were expressed. Could land use and land cover (LULC) analysis be used as an indirect indicator of soil carbon? Could remote sensing be used to monitor soil carbon? Could biodiversity be a surrogate for water quality? Such questions need to be answered to maximize the cost-benefit assessment of impacts.

There was agreement that biological diversity indicators are the least developed but should include those measuring benefits to society and function. The number of species on endangered lists may be an indicator, but unfortunately species are placed on the lists by political will, not science.

Social acceptance is another indicator area that was discussed. Using surveys was considered acceptable, but results need to be cross-validated. Indicators of social acceptance such as the happiness index exist, but longitudinal analysis is needed. It was noted that social acceptability is more like a negotiation or process than an indicator. Within economic indicators, a focus on profits was thought not to be reflective of the environmental and educational value. Good economic indicators would be productivity and the biomass-to-biofuel conversion factor.

In general, the need for experimentation was noted, even if it implies making mistakes, as long as soil is not damaged in the process. The experience of Land Labs (Jordan et al. 2013) was cited as a good example to consider.

\subsubsection{What are the next steps? How can we establish holistic initiatives at watershed or other local scales to demonstrate and promote the benefits of landscape-based bioenergy systems?}

A set of concrete actions was proposed by workshop participants during the second day. The first action priority was to develop case studies. Case studies are needed, as well as an information platform that can be connected to a range of potential uses. A pilot test and proof-of-concept initiative in a target area (e.g., a particular state) could be a good start and should include bioenergy among other components. Public-private partnerships should be increased to support pilot-test initiatives at the local level.

Another important action is to address supply chain obstacles. Creating demand for biomass is a key step. A diversity of end uses and scales of end uses are needed. Resolving the chicken-or-the-egg causality issue by addressing two or more parts of the supply chain simultaneously is difficult. Ideas for creative initiatives may look at available examples such as BCAP (which requires producers and users to agree on a timeline). The DOE "Clean Cities" project might be a good model for activating the public on a community-by-community basis.

The action needs to be at three levels: (1) a national-level group to develop a vision, (2) a local-level group to work on cultural and social practices specific to that context, and (3) an implementation-level group to work with the Natural Resources Conservation Service (NRCS), technical service providers, and other compatible organizations.

Technical action items include developing a good integration-into-cropping system ready for use in the field, developing spatial design as a key tool for assembling cropping systems that unite biophysical and socioeconomic systems, and increasing the power of research through meta-analysis that fully harnesses existing literature. Finally, interacting internationally is important for capitalizing on global experiences.

Partnerships were proposed to (1) move researchers outside the fence and create communities of growers, academics, researchers, and markets; (2) develop and test long-term contracts to de-risk opportunity; and (3) establish partnerships with those who value the Conservation Reserve Program (CRP) for wildlife. Programs such as the USDA Ag Tech Innovation Partnership could be considered as a model platform. There are nine groups around the country focused to move USDA technologies into the private sector. The USDA formed a foundation to assist in the funding of these research projects; it now has two projects. Another strategy is to involve place-based nongovernmental 
organizations that care about landscape design. Adding a valuation and incentives component would help to make things happen better than imposing a heavy regulatory hand.

The following ideas on what the workshop group could do were also offered:

- Work as a group toward identifying a common vision.

- Make sure that connectivity works well. Evolve forward, going from a focus on information to development of an action list.

- Follow up with network-building activities. Reduce information barriers by developing an e-mail list with both workshop participants and others to keep the discussion alive.

- Consider participating in the rural landscape state conference in Illinois in the fall of 2016.

On the policy front, the consensus was that policies need to be supportive, not regulatory, and some form of economic incentive is needed to develop a level playing field with existing agricultural crops. Basically, participants identified two main policy areas for intervention: (1) crop insurance and (2) compensation for the provisioning of ecosystem services beyond crop production or support for trading systems. The real policy direction for crop insurance was thought to be removing disincentives to plant only row crops, rather than insuring the energy crop. However, to develop crop insurance related to bioenergy crops, there is a need for actual field performance data. Since 2008, data from the Farm Service Agency have been difficult to obtain, and it is unclear what data are owned by insurance companies.

A critical analysis and continuous improvement of existing programs are also needed. Currently, if a crop is harvested from CRP-enrolled land, the payment is reduced by the amount of money obtained from the sale of the crop. This restriction does not acknowledge the fact that ecosystem services are not reduced to zero by harvesting. CRP's successors must move past the zero-sum approach. An ecosystems provision-based payment scheme could help solve this problem. For new policies, it was deemed important not to wait to have something that is perfect, but to start with a process for adaptive revision and correction. Challenge grants could be offered to move the technology forward. Further internationalization would also be desirable.

Tangible next steps and research needs include the following:

- Network. Connect the expertise of DOE's national laboratories on supply chain and other topics to operators and ensure continuing dialogue among people in this group.

- Learn. Find ongoing projects. Determine what is doable. Assemble a collection of examples and case studies and organize them into a communicable structure.

- Communicate. Publicize energy conversion technologies, including small to medium heating equipment, that will burn grass biomass. Work with existing partners to publicize case studies.

- Study.

- DOE and USDA should conduct an analysis of expiring CRP acres to identify opportunities for landscape design. There are perhaps 8 million acres in grass cover likely to be converted to corn. DOE and USDA should find where they are and where they coincide with resource needs and with existing or alternative proposed end uses.

- Link existing field research on bioenergy crops to economic modeling tools.

- Develop inputs and outputs; develop quantitative life-cycle analyses.

- Develop new varieties of bioenergy crops; for example, all of North America has the same miscanthus plant, and lack of diversity means these plants are susceptible to the same diseases.

- Develop U.S.-based combustion technology to support local markets to avoid using European technology for a biomass burner. 
- In the process of "improving" native grasses and species, focus not only on yields but also on ecosystem services abilities. For example, water-tolerant bioenergy perennials that can renaturalize and treat drainage system should be studied and introduced.

- Find more efficient ways to perform quick sensitivity analyses, which are now difficult to conduct with current water quality models; try different patterns. Simple models are bad for sensitivity analyses; more complex models and more training are needed; and the functions of models need to be expanded.

- Develop iterative research-commercialization-supply chain approaches.

- Highlight connections between watershed management and development. 


\section{Conclusions and the Way Forward}

Landscape design for bioenergy is starting to come to focus as an opportunity for achieving sustainability while growing bioenergy crops, and this workshop allowed many different fields of science to come together that have traditionally worked separately. Experiences from different fields such as conservation can provide a knowledge base for developing sustainable bioenergy and integrated landscapes. Workshop participants were unanimously supportive of developing integrated landscape design for bioenergy production.

To realize this opportunity, it is important to expand the conversation from the research environment to the broader stakeholder community. A necessary step is to begin a process of language harmonization so that a common set of definitions and goals is used by researchers, producers, regulators, biomass users, businesses, and the public. This inclusive process of communication and a continuous feedback loop will ultimately deliver solutions that are doable and acceptable.

A supportive rather than a prescriptive policy approach is most likely to produce positive results. Policies that mitigate risk (such as crop insurance) are critical. Economic opportunities could be closer than we think-energy crops do not have to make money outright to increase the bottom line of farmers. Even if farmers lose money, the effect on their finances can be positive if they displace another less profitable option, particularly at the subfield level. The need is to find ways to provide sufficient information to allow farmers to make good decisions. Other supporting economic opportunities that could be critical to the implementation of landscape design lie in the recognition and valuation of the ecosystems services that bioenergy crops can provide. To that end, better data on what benefits can be achieved are necessary to support and validate trading mechanisms and find the correct ways to place a value on the services provided. Certification will be the basis for the recognition of a "sustainable" status and perhaps from the future of ecosystems services provided.

Markets are essential to the development of sustainable biofuels and, therefore, also of integrated landscape design. Opportunities for market synergisms, such as that of bioenergy and feed, need to be supported to advance the establishment of a bioeconomy. Workshop participants unanimously believed that implementation and development of bioenergy landscape design have to start small. A tangible realistic outcome, suitable for management by an extension office, is to define a market entry point within a series of real operations (heating systems, feed, bedding, bioenergy, etc.). Farmers and landlords should be engaged by providing them with decision tools that can save money or improve financial outcomes, so that the plan becomes successful in a short timeframe (three years). Moreover, the operation should be refined until it is successful, and then it should be passed along to others. These actions need to include what can be done both at the farm level and at later stages of the supply chain (e.g., developing markets). If both of these stages are not supported, then long-term development is unlikely. The DOE-supported Advanced Uniform Format is conducive to promoting integrated landscape designs, because this format organizes the logistics of small, distributed amounts of biomass produced on a diversified landscape, and preprocesses them in local depots to obtain biomass suitable for a variety of end uses.

From a perception standpoint, landscape design could be positively received as "design," implying that it's in one's sphere of influence. Farmers who think they are disempowered by knowing they contribute to Gulf Hypoxia could be empowered by thinking of what they can do within their landscape that benefits not only them but also others. Farmers are interested in this approach and appreciate the value, but some practices may conflict with what is perceived as efficient agriculture, such as the use of larger equipment that is not suitable for smaller landscape portions dedicated to different crops.

Partnerships are needed to achieve good landscape design where biomass production is a primary objective. Workshop participants provided a list of concrete action ideas that could be started in the near term:

- Develop a value proposition for land managers and show how it works on an individual stakeholder's scale.

- Develop a plan to obtain and communicate data to the world. Assemble a collection of case studies and distribute as videos, tours, and other media. View the examples to generate ideas.

By implementing these actions, participants believed that progress could be made in developing the science and practice of designing sustainable landscapes that incorporate bioenergy. 
(This page intentionally left blank) 


\section{References}

Bioenergy Technologies Office (2015). Bioenergy Technologies Office Multi-Year Program Plan, March 2015. DOE/ EE-1193.http://energy.gov/eere/bioenergy/downloads/bioenergy-technologies-office-multi-year-program-plan-march2015-update.

U.S. Environmental Protection Agency (2013). "National Rivers and Streams Assessment." http://water.epa.gov/type/rsl/monitoring/riverssurvey.

Follett, R. et al. (2012). "Soil Carbon Sequestration by Switchgrass and No-Till Maize Grown for Bioenergy." BioEnergy Research (5:4); 866-875.

Jaynes, D.B.; James, D.E. (2007). “The Extent of Farm Drainage in the United States.” In final program and abstracts, Soil and Water Conservation Society 2007 International Conference, July 21-25, 2007, Tampa, FL. http://www.ars.usda.gov/SP2UserFiles/Place/50301500/TheExtentofFarmDrainageintheUnitedStates.pdf.

Jenkins, W.A. et al. (2010). "Valuing ecosystem services from wetlands restoration in the Mississippi Alluvial Valley.” Ecological Economics (69:5); pp. 1051-1061.

Jordan, N.; Schulte, L.; Williams, C.; Mulla, D.; Pitt, D.; Slotterback, C.S.; Jackson, R.; Landis, D.; Dale, D.; Becker, D.; Rickenbach, M.; Helmers, M.; Bringi, B. (2013). "Landlabs: An integrated approach to creating agricultural enterprises that meet the triple bottom line." Journal of Higher Education Outreach and Engagement $(17: 4)$.

Keeler, B.L. et al. (2013). "U.S. federal agency models offer different visions for achieving Renewable Fuel Standard (RFS2) biofuel volumes.” Environmental Science \& Technology (47:18); pp. 11095-10101.

Nassauer, J.I.; Corry, R. (2004). “Using normative scenarios in landscape ecology.” Landscape Ecology (19:4); pp. 343-356.

Nassauer, J.I.; Santelmann, M.V.; Scavia, D., eds. (2007). From the Corn Belt to the Gulf: Societal and Environmental Implications of Alternative Agricultural Futures. New York: Routledge. 272 pp.

Osmond, D.; Meals, D.; Hoag, D.; Arabi, M., eds. (2012). How to Build Better Agricultural Conservation Programs to Protect Water Quality: The National Institute of Food and Agriculture-Conservation Effects Assessment Project Experience. Ankeny, IA: Soil and Water Conservation Society. 387 pp.

Schmer, M.R. et al. (2008). "Net energy of cellulosic ethanol from switchgrass." Proceedings of the National Academy of Sciences (105:2); pp. 464-469.

Shortall, O.K. (2013). “"Marginal land' for energy crops: Exploring definitions and embedded assumptions." Energy Policy (62); pp. 19-27. http://www.researchgate.net/publication/262116473_Marginal_land_for_energy_crops_Exploring definitions_and_embedded_assumptions.

Tomer, M.D.; Locke, M.A. (2011). "The challenge of documenting water quality benefits of conservation practices: a review of USDA-ARS's conservation effects assessment project watershed studies." Water Science \& Technology (64:1); pp. 300-310. http://naldc.nal.usda.gov/download/49869/PDF.

Wallander, S.; Claassen, R.; Nickerson, C. (2011). The Ethanol Decade: An Expansion of U.S. Corn Production, 2000-09. U.S. Department of Agriculture Economic Research Service.

Werling, B.; Dickson, T.; Isaacs, R.; Gaines, H.; Gratton, C.; Gross, K.; Liere, H. et al. (2013). "Perennial grasslands enhance biodiversity and multiple ecosystems services in bioenergy landscapes." Proceedings of the National Academy of Sciences (111:4); pp. 1652-1657. http://www.pnas.org/content/111/4/1652.short.

Werling, B.P. et al. (2011). "Biocontrol potential varies with changes in biofuel-crop plant communities and landscape perenniality.” GCB Bioenergy (3:5); pp. 347-359. 
(This page intentionally left blank) 


\title{
Appendices
}

\section{A. Workshop Agenda}

u.s. DEPARTMENT OF | Energy Efficiency \&

ENERCY Renewable Energy

\section{BIOENERGY TECHNOLOGIES OFFICE}

\section{Incorporating Bioenergy in Sustainable Landscape Designs Workshop Two: Agricultural Landscapes}

\author{
June 24-26, 2014 | Argonne National Laboratory \\ 9700 S. Cass Avenue I TCS Conference Center \\ Argonne, IL 60439
}

\section{WORKSHOP OBJECTIVE}

The second edition of the Sustainable Bioenergy Landscapes Workshop will convene a discussion on the usefulness and feasibility of using landscape principles to design sustainable bioenergy/row crop systems in the U.S. midwestern agricultural landscape. Through the workshop, participants are expected to develop an understanding of the state of the science, research needs, tools, and methodologies for the demonstration and monitoring of prototype landscape bioenergy systems across the supply chain in the midwestern corn-belt region.

DAY 1-TUESDAY, JUNE 24, 2014: FIELD TOUR

- Argonne field study site-Fairbury, Illinois

- View a landscape design field study centered around the use of biomass to recover and reuse nitrogen lost by adjacent corn. The demonstration of precision agriculture tools to aide in the placement of bioenergy crops and an illustration of watershed scale conservation initiatives organized by the Conservation Technology Information Center will also be covered in the landscape design field study.

8:00 a.m.-4:30 p.m. U.S. Department of Agriculture's (USDA's) National Center for Agricultural Utilization Research (NCAUR)-Peoria, Illinois

- Learn about research on new bioenergy winter cover crops (pennycress) and tour their pilot-oil extraction facility.

- Chip Energy-Goodfield, Illinois

- Visit a modular biomass depot facilty built with recycled shipping

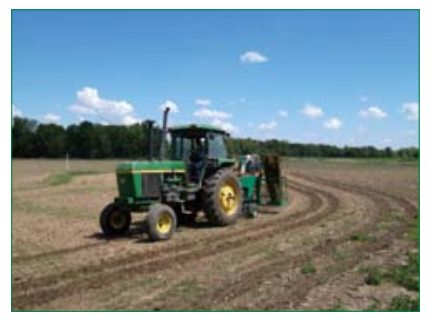

Willow buffer being planted in a corn field. containers where lignocellulosic biomass is collected and processed for further distribution to end users.

DAY 2-WEDNESDAY, JUNE 25, 2014: WORKSHOP

Introduction to the workshop

- Welcome to Argonne-Donald Hillebrand

- Welcome-Alison Goss Eng

8:30 a.m.-9:00 a.m.

- Workshop goals and Bioenergy Technologies Office introduction-Kristen Johnson and Mark Elless

- Round of introductions-All participants

- Recap from Workshop 1: Incorporating Bioenergy into Sustainable Landscape Designs-Virginia Dale

The midwestern landscape

- Midwest agriculture land use history and pressures on land use decisions-Harold Reetz

9:00 a.m.-10:00 a.m. Biomass resources in the midwest region-Kim Mullins

- Environmental concerns in midwest agricultural landscapes-Roberta Parry

- Marginal land in the midwest-Rob Mitchell

Break and poster session

- Flame Energy-Eric Rund

- Agricultural Watershed Institute-Steve John

10:00 a.m.-10:30 a.m.

- Conservation Technology Information Center-Chad Watts

- Illinois Biomass Working Group-Fred lutzi

- USDA NCAUR

- Precision Agriculture-Veris

- Chip Energy-Paul Wever 


\begin{tabular}{|c|c|}
\hline 10:30 a.m.-11:30 a.m. & $\begin{array}{l}\text { Designing sustainable bioenergy/grain landscapes: Research methods and experiences } \\
\text { - Designing for environmental and socioeconomic sustainability-Cristina Negri } \\
\text { - Using future landscape scenarios to communicate among disciplines and stakeholders-Joan Nassauer } \\
\text { - Sustainable corn stover harvest strategies for midwest agricultural landscapes-Doug Karlen } \\
\text { - Bridging scales and tools in the field, watershed, county, and region-David Muth }\end{array}$ \\
\hline 11:30 a.m.-12:30 p.m. & $\begin{array}{l}\text { Panel: Assessing impacts, benefits, methods, and results } \\
\text { - Experiences from the Agricultural Research Service Croplands Conservation Effects Assessment Project } \\
\text { program-John Sadler } \\
\text { - Biodiversity-related ecosystem services in bioenergy landscapes-Claudio Gratton } \\
\text { - Monitoring approaches to assess sustainability metrics at the field and watershed scale-Jeff Volenec } \\
\text { - Connecting integrated landscape management with feedstock logistics-lan Bonner } \\
\text { - Air quality considerations for bioenergy landscapes-Garvin Heath }\end{array}$ \\
\hline 12:30 p.m.-1:30 p.m. & Working Lunch: Food and Sustainable Biofuels: Thinking clearly about the issues-Bruce Dale \\
\hline 1:30 p.m.-2:30 p.m. & $\begin{array}{l}\text { Policy, economics, and societal interests } \\
\text { - Promoting Bioenergy Crops: An economic perspective on challenges and opportunities-Silvia Secchi } \\
\text { - The Biomass Crop Assistance Program-Kelly Novak } \\
\text { - Economic sustainability and ecosystems services valuation-Randy Jackson } \\
\text { - The Nature Conservancy's experiences in the Midwest: Managing agricultural landscapes for wildlife } \\
\text { and water quality - David DeGeus }\end{array}$ \\
\hline 2:30 p.m.-3:15 p.m. & $\begin{array}{l}\text { Breakout groups (there will be four breakout groups) } \\
\text { - Is landscape design the course of action needed to move forward and if so, how can it be implemented? } \\
\text { - Do we have the design and monitoring tools that we need? What are we missing? }\end{array}$ \\
\hline 3:15 p.m.-3:30 p.m. & Break and poster session \\
\hline 3:30 p.m.-4:45 p.m. & $\begin{array}{l}\text { Panel roundtable: Buy-in across the supply chain } \\
\text { - Bruce Dale } \\
\text { - } \quad \text { Farmer's perspectives-Eric Rund, Norm Larson, Bob Stewart } \\
\text { - Industry perspectives-Mark Henson, Monsanto } \\
\text { - The POET approach-Alex Johnson } \\
\text { - Illinois Institute of Rural Affairs and Illinois Biomass Working Group-Fred lutzi }\end{array}$ \\
\hline 4:45 p.m.-5:30 p.m. & Breakout groups report to workshop and discussion \\
\hline 5:30 p.m. & Adjourn \\
\hline \multicolumn{2}{|c|}{ DAY 3-THURSDAY, JUNE 26, 2014: WORKSHOP } \\
\hline 8:00 a.m.-8:30 a.m. & Previous day recap and instructions to breakout groups \\
\hline 8:30 a.m.-9:15 a.m. & $\begin{array}{l}\text { Breakout groups reconvene } \\
\text { - What are the next steps? How can we establish holistic initiatives at watershed or other local scales to } \\
\text { demonstrate and promote the benefits of landscape based bioenergy systems? }\end{array}$ \\
\hline 9:15 a.m.-10:15 a.m. & $\begin{array}{l}\text { Certification, standards, and international perspectives } \\
\text { - Landscape design in the sugarcane based ethanol production systems in Brazil-Regis Leal } \\
\text { - Developing U.S. Sustainability Certification Standards to measure landscape-level sustainability-Jody Endres } \\
\text { - Roundtable on Sustainable Biomaterials-Matthew Rudolph } \\
\text { - Best management guidelines to achieve sustainability of wildlife resources-Aviva Glaser }\end{array}$ \\
\hline 10:15 a.m.-10:30 a.m. & Break \\
\hline 10:30 a.m.-11:30 a.m. & Breakout groups report to workshop \\
\hline 11:30 a.m.-12:15 p.m. & Plenary discussion and action plan: What are the research needs and tangible next steps? \\
\hline 12:15 p.m. & Adjourn \\
\hline
\end{tabular}




\section{B. Workshop Participants}

\section{First Name \\ Last Name \\ Company}

\begin{tabular}{|c|c|c|}
\hline Daniel & Adams & BCS, Incorporated \\
\hline Ian & Bonner & Idaho National Laboratory \\
\hline Max & Broad & BCS, Incorporated \\
\hline Fred & Circle & FDC Enterprises Inc. \\
\hline Bruce & Dale & Michigan State University \\
\hline Virginia & Dale & Oak Ridge National Laboratory \\
\hline David & De Geus & The Nature Conservancy \\
\hline Mark & Elless & U.S. Department of Energy, Bioenergy Technologies Office \\
\hline Jody & Endres & University of Illinois at Urbana-Champaign \\
\hline Aviva & Glaser & National Wildlife Federation \\
\hline Alison & Goss Eng & U.S. Department of Energy, Bioenergy Technologies Office \\
\hline Claudio & Gratton & University of Wisconsin-Madison \\
\hline $\operatorname{Jim}$ & Gulliford & Soil and Water Conservation Society \\
\hline Garvin & Heath & National Renewable Energy Laboratory \\
\hline Mark & Henson & Monsanto \\
\hline Donald & Hillebrand & Argonne National Laboratory \\
\hline Terry & Isbell & USDA National Center for Agricultural Utilization Research \\
\hline Fred & lutzi & Illinois Institute for Rural Affairs \\
\hline Randall & Jackson & Great Lakes Bioenergy Research Center, University of Wisconsin-Madison \\
\hline Henriette & Jager & Oak Ridge National Laboratory \\
\hline Stephen & John & Agricultural Watershed Institute \\
\hline Alex & Johnson & POET Biomass \\
\hline Kristen & Johnson & U.S. Department of Energy, Bioenergy Technologies Office \\
\hline Douglas & Karlen & USDA Agricultural Research Service \\
\hline Keith & Kline & Oak Ridge National Laboratory \\
\hline Norm & Larson & Larson Farms \\
\hline Manoel Regis & Leal & Brazilian Bioethanol Science and Technology Laboratory \\
\hline Shelie & Miller & University of Michigan \\
\hline Rob & Mitchell & USDA Agricultural Research Service \\
\hline Kimberley & Mullins & University of Minnesota \\
\hline Michael & Musselman & FarmMap Solutions, LLC \\
\hline David & Muth & AgSolver, Inc \\
\hline
\end{tabular}




\section{First Name}

Last Name

Company

\begin{tabular}{l|l|l}
\hline Joan & Nassauer & University of Michigan \\
\hline Cristina & Negri & Argonne National Laboratory \\
\hline Kelly & Novak & USDA Farm Service Agency \\
\hline Roberta & Parry & U.S. Environmental Protection Agency \\
\hline Harold & Reetz & Reetz Agronomics, LLC \\
\hline Matthew & Rudolf & Roundtable on Sustainable Biomaterials \\
\hline Eric & Rund & Rund Farms, Green Flame Energy \\
\hline John & Sadler & USDA Cropping Systems and Water Quality Research Unit \\
\hline Amy & Schwab & National Renewable Energy Laboratory \\
\hline Tom & Schwartz & FDC Enterprises, Inc. \\
\hline Silvia & Secchi & Southern Illinois University \\
\hline Bob & Stewart & Stewart Farms \\
\hline Steven & Thomas & U.S. Department of Energy, Bioenergy Technologies Office \\
\hline Mark & Tomer & USDA Agricultural Research Service \\
\hline Scott & Tomkins & Illinois Environmental Protection Agency \\
\hline Jeff & Volenec & Purdue University Department of Agronomy \\
\hline Timothy & Volk & SUNY ESF \\
\hline Chad & Watts & Conservation Technology Information Center \\
\hline Paul & Wever & Chip Energy Inc. \\
\hline Gwen & White & Eastern Tallgrass Prairie \& Big Rivers LCC \\
\hline May & Argonne National Laboratory \\
\hline
\end{tabular}

\section{Workshop Presentations}

1. Workshop Goals and Bioenergy Technologies Office Introduction—Kristen Johnson and Mark Elless

2. Recap from Workshop 1: Incorporating Bioenergy into Sustainable Landscape Designs—Virginia Dale \& Keith Kline

3. Midwest Agriculture Land Use History and Pressures on Land Use Decisions—Harold Reetz

4. Biomass Resources in the Midwest Region-Kim Mullins

5. Environmental Concerns in Midwest Agricultural Landscapes-Roberta Parry

6. Marginal Land in the Midwest—Rob Mitchell

7. Flame Energy-Eric Rund

8. Agricultural Watershed Institute—Steve John

9. Illinois Biomass Working Group - Fred Iutzi

10. Designing for Environmental and Socioeconomic Sustainability—Cristina Negri 
11. Using Future Landscape Scenarios to Communicate among Disciplines and Stakeholders-Joan Nassauer

12. Sustainable Corn Stover Harvest Strategies for Midwest Agricultural Landscapes-Doug Karlen

13. Bridging Scales and Tools in the Field, Watershed, County, and Region-David Muth

14. Experiences from the Agricultural Research Service Croplands Conservation Effects Assessment Project Program-John Sadler

15. Biodiversity-Related Ecosystem Services in Bioenergy Landscapes-Claudio Gratton

16. Monitoring Approaches to Assess Sustainability Metrics at the Field and Watershed Scale_Jeff Volenec

17. Connecting Integrated Landscape Management with Feedstock Logistics—Ian Bonner

18. Air Quality Considerations for Bioenergy Jandscapes—Garvin Heath

19. Food and Sustainable Biofuels: Thinking Clearly About the Issues-Bruce Dale

20. Promoting Bioenergy Crops: An Economic Perspective on Challenges and Opportunities-Silvia Secchi

21. The Biomass Crop Assistance Program-Kelly Novak

22. Economic Sustainability and Ecosystems Services Valuation-Randy Jackson

23. The Nature Conservancy's Experiences in the Midwest: Managing Agricultural Landscapes for Wildlife and Water Quality-David DeGeus

24. Farmer's Perspectives-Eric Rund

25. Industry Perspectives-Mark Henson

26. The POET Approach-Alex Johnson

27. Landscape Design in the Sugarcane Based Ethanol Production Systems in Brazil-Regis Leal

28. Developing U.S. Sustainability Certification Standards to Measure Landscape-Level Sustainability-Jody Endres

29. Roundtable on Sustainable Biomaterials-Matthew Rudolf

30. Best Management Guidelines to Achieve Sustainability of Wildlife Resources-Aviva Glaser

\section{Participant Responses}

Participants were asked to respond to three questions about the workshop:

1. How do you define landscape design?

2. What can you contribute to the field of landscape design?

3. What would you commit to over the next year to develop the field of landscape design?

Participants' responses are summarized in table D-1: 
Table D-1. DOE Landscape Design Workshop-Participant Responses

\section{Q1. What does landscape design mean to you? \\ Landscape Design is a method of organizing a systems approach to the implementation of landscape-scale land uses. a. Allows for careful planning to target the most appropriate acres, species, markets, and methods that will be used to implement. b. Enables organizers to evaluate the existing systems to develop outreach and implementation strategies that integrate well with those systems and the communities and individuals who will be implementing various desired land use changes}

Landscape Design: optimize land use in watershed or regional scale to maximize economic, social, and environmental benefits and minimize drawbacks.

Putting right crop (plants) in the right place for right person to produce an economically viable, environmentally sustainable, and socially acceptable U.S. agriculture

Using landscape-level approach to land use planning that incorporates ecological context (i.e. watersheds, wildlife, etc.) and economic and environmental sustainability.

Spatial pattern, shapes, sizes of different crops and management practices on landscape

Strategic deployment of biomass systems

\section{Q2. What can you contribute?}

I can contribute experiences from implementation in Indian Creek and my experiences relating with farmers to help with outreach and technical assistance strategies and implementation

In my capacity at BETO, I can argue for funding to support landscape design research and devlopment and demonstrations.

Plan to incorporate landscape design into next generation of USDA Agricultural Research Service (ARS) project plans for National Laboratory for Agriculture and Environment

Knowledge and resources on wildlife and biodiversity, network of natural resource professionals with knowledge of sustainable bioenergy, willingness to learn and collaborate

Theoretical ecology background and knowledge of quantitative analysis

Data, modeling, research infrastructure that is unique; knowledge, metaanalysis. In agro ecology, agronomy; fix Soil and Water Assessment Tool modeling, water quality, biogeochemical cycling of C, $\mathrm{N}, \mathrm{H}_{2} \mathrm{O}$.
Q3. What is your commitment over the next year?

In the next year, Conservation Technology Information Center will work within the Indian Creek project to help engage farmers in the discussion and implementation of biofuels.

Always available for discussion, planning, and execution of concrete plans, experiments, and demonstrations

Will provide data-plot, field, and watershed scale information for various feedstock production practices

Commitment over next year: Engage with group and collaborate on issues of landscape design for bioenergy, provide resources on wildlife impacts, etc.

High interest! Collaborate/ plan 


\section{Q1. What does landscape design mean to you?}

andscape Design includes the engagement of multiple stakeholders, the identification of their objectives, and the design of systems across the landscape that address as many of these objectives as possible.

A concept that seeks to establish a resource utilization system that provides the necessary economic profitability, appropriate goods and services, sustainability of natural resources, and environmental performance within a free market system that a free market system that recognizes the rights of the landowner to make these decisions.

Large-scale (watershed or larger) planning that incorporates land cover, management practices, supply, and social systems

We are interested in model, data, and analysis of changes of the agricultural landscape with a focus on water quality and hydrology. Specifically, we have strong capabilities of SWAT modeling and other hydrologic models at field, watershed, and river basin scale, and are available to assist next year.

Intentional change in landscape patterns, composition, or management at any scale. It also means the process of making decisions about this intentional landscape change.
Q2. What can you contribute?

Provide data and perspectives on short rotation woody crops, environmental benefits and impacts, etc., potential areas for demonstration (areas with about 1,200 acres of willow biomass crops in Northern New York), opportunity for assessments of sustainability and various impacts at a larger scale than field plots.

I would like to be involved in educational and outreach efforts.

Adoption modeling, lifecycle analysis, systems analysis

I can contribute methods of alternative scenario design and integrated assessment of these designs, including stakeholder engagement and measurement of social science responses.
Q3. What is your commitment over the next year?

Interested in engaging in landscape modeling for SRWC using a landscape design modeling approach

Interested in collaboration, various forms of engagement

I will stay involved in discussions as necessary. 


\section{Q1. What does landscape design mean to you?}

The term sounds like zoning regulation to reflect government/society goals. It might be worthwhile to work with a farmer focus group to develop a term that would resonate with that community.
An organized approach with appropriate tools and procedures to formulate a plan for modifying the cropping system to include new crops end management practices such as biofuel chops.

Management of land at a field or subfield level that takes into account its impacts on a watershed level

Intentional incorporation of biomass feedstock production into conventional agriculture with the aims of improving soil and water quality and increasing energy output from agriculture
Taking a big picture view of the landscape to identify best use of land for productive use, considering economic and environmental parameters. Strategic land use planning to optimize for yield, value, and environmental performance

\section{Q2. What can you} contribute?

To the extent that bioenergy production can be part of a solution for nutrient water quality problems, I can help make links with programs/ policies that are focused on this: state 310 progress, water quality trading, i.e., Ohio River Sanitation Commission in the Ohio River Basin, Hypoxia task force, connection to the Nutrient Challenge workgroup (federal level with White House involvement)

Help to develop examples, implement demonstrations, and educate farmers on their decisions.

Policy development to allow for measurement of ecosystem services that can then be monetized.

Incorporation of key metrics, including energy and water consumption into life-cycle analysis of landscape design and conventional design agriculture. Thinking through how "emerging" metrics, e.g., biodiversity and social acceptance, etc., can be incorporated into life-cycle analysis

Stakeholder engagement, verification of activities (are farmers and companies doing what they are saying they are doing?)
Q3. What is your commitment over the next year?

Willing to participate in discussion to help shape the initiative to tap into water quality focused resources

Very much interested in being a part of a team to plan, implements, and evaluate this kind of activity. Help identify and guide selected farmers and their advisers.

Collaboration through conference call or webinar. A normal conference meeting

Collaborate on evaluation of landscape design within life-cycle analysis 


\section{Q1. What does landscape design mean to you?}

his idea brings some negative connotations to me. The farmer in me gets a little defensive, feeling like someone is telling me what to do. We need to figure out how to present this in a positive light to landowners.

Landscape design is the precision placement of management and practices to maximize profitability and environment performance simultaneously.

Landscape design, to me, is finding ways to utilize land so it provides ecological or societal benefits while also maintaining productivity and profitability. I think there are ways to balance those goals so that all stakeholders can feel comfortable with the final design.

Landscape design means deliberately engineering the topography of the land and the types of plants that grow on the land to achieve specific defined outcomes.

Increasing the efficiency of resource use to meet the needs of near- and long-term users

\section{Q2. What can you} contribute?

Data, collaboration on modelling efforts, field scale, perennial grass sites, grazing information, multiple feedstocks for trials, NIRS lab analysis

Decision tools that identify and explore the impacts of alternative management systems

I will push my research group to explore different sources of biomass. This will help define what works within our process, which should lead to tangible markets for biomass

To promote the concept within my organization

Extend data availability and outreach to promote science-based decisions for land managers and facilitate collaborative research
Q3. What is your commitment over the next year?

I'm willing to collaborate with interested parties as time allows

Participate in discussion, provide data and tools

I can commit to collaboration with research efforts when it's feasible and doesn't compromise confidentiality. I would also be open to landscape design discussions and ways in which we could support development of landscape design in our area (market for biomass)

To stay informed and advocate for the development of supply chains for biomass that are truly sustainable.

Idaho National Laboratory is working with industry, institutes, and other national laboratories to create/expand foundational data loges and deployable tools to promote awareness of potential impacts (both positive and negative) of integrating energy crops into row crop landscapes 


\section{Q1. What does landscape design mean to you? \\ The opportunity for a landowner or operator to understand in detail the ecosystem value of their land, the opportunity for landscape design nongovernmental organizations to work with landowners/operators in realizing the ecosystem valuation of their lands and adjusting land management and practice instillation planning to effectively use their lands or care for their lands and an opportunity for private/ public partnerships to enable the NGOs and landowners/operators the space to put the plans for landscape design into implementation.}

Identifying components and placing them in configurations to achieve an ecosystem service goal or suite of goals

I guess I focus on the "design" aspect of this term most strongly, as I have an engineering background and approach to problem solving. In this context, landscape design suggests a planned, structured layout of potentially many land use/land covers-whatever is necessary to achieve the land owners/users goals. Depends on analysis and on good definition of objectives (and how to see if those objectives were met).

To consciously think about all the ecosystem services/functions we want to manage the land for and to create policies/tools that work and are effective in promoting that landscape

\section{Q2. What can you contribute?}

Offer landowners and operators assistance to establish perennial or annual crops or assistance with collection/harvest of agricultural or forest residues for bioenergy conversion processes

USDA-ARS in Columbia, Missouri, has several bioenergy-relevant research projects examining productivity (landscape characteristics). We also have SWAT and APEX modeling work that is relevant. We also work in the targeting of best management practice placement arena.

Modelling work (some existing on switchgrass production irrigation) and policy analysis (assessment of effectiveness in achieving policy goals)

\section{Expertise in the} conservation policy integrated economic/water quality (SWAT) modeling. We have data on several Midwestern water sheds and are simulating changes in water quality associated with different landscapes (more corn, more switchgrass) under various climate scenarios.

\section{Q3. What is your} commitment over the next year?

Work with planning a policy management to consider landscape design in practice and strategic planning, as well as an activity for the purposes of meeting global change management goals and conservation goals.

USDA-ARS is committed to the proceed listed in \#2 above. These are long-term projects.

Modelling work in collaboration would be a lot of fun!

I would be delighted to keep collaborating on these issues and share results 


\section{Q1. What does landscape design mean to you?}

Landscape design means the deliberate value-
driven choice of what and when to plant on
managed landscapes to achieved desired
objectives
Landscape design is a spatially explicit, place-
based collaborative plan for integrated resource
management (soil, biomass, water) seeking to
promote more sustainable practices responsive
to local priorities and context

Landscape design actions taken by an actor/ decision maker within his/her sphere of influence to change the surrounding physical environment to accomplish a set of objectives and purposes. The boundary of the landscape is set by the horizon of the individual or group actors based on their real or perceived influence boundaries.

Landscape design to me means use each parcel of land to its best advantage in terms of preserving that piece of land, the environmental impact it may have, its profitability, and benefits to wildlife and society.

\section{Q2. What can you contribute?}

Experimental/modeling work on biomass processing depots. LCA to evaluate various scenarios for bioenergy landscape design

Case studies/research on landscape design approach and analysis applied to forests in SE USA

Introduce people with technologies, data, and models to land stewards/ producers. Set up events for rich flow of information and development of relationships, focus planning and DOE efforts on data

We are growing Miscanthus and other biomass and developing markets for these crops. We try to share what we have learned-the mistakes as well as the successes.

\section{Q3. What is your} commitment over the next year?

Complete enthusiasm and commitment to the project!

Depends on availability of DOE support, but hopefully includes outreach, publications, analysis.

Keep long-range planning tether to practical realities-refuse to settle for either/or false choices. Data, data, data

Almost the same as above. I will continue to exchange ideas with others doing the same, and continue to try new ideas on our farm. 
(This page intentionally left blank) 



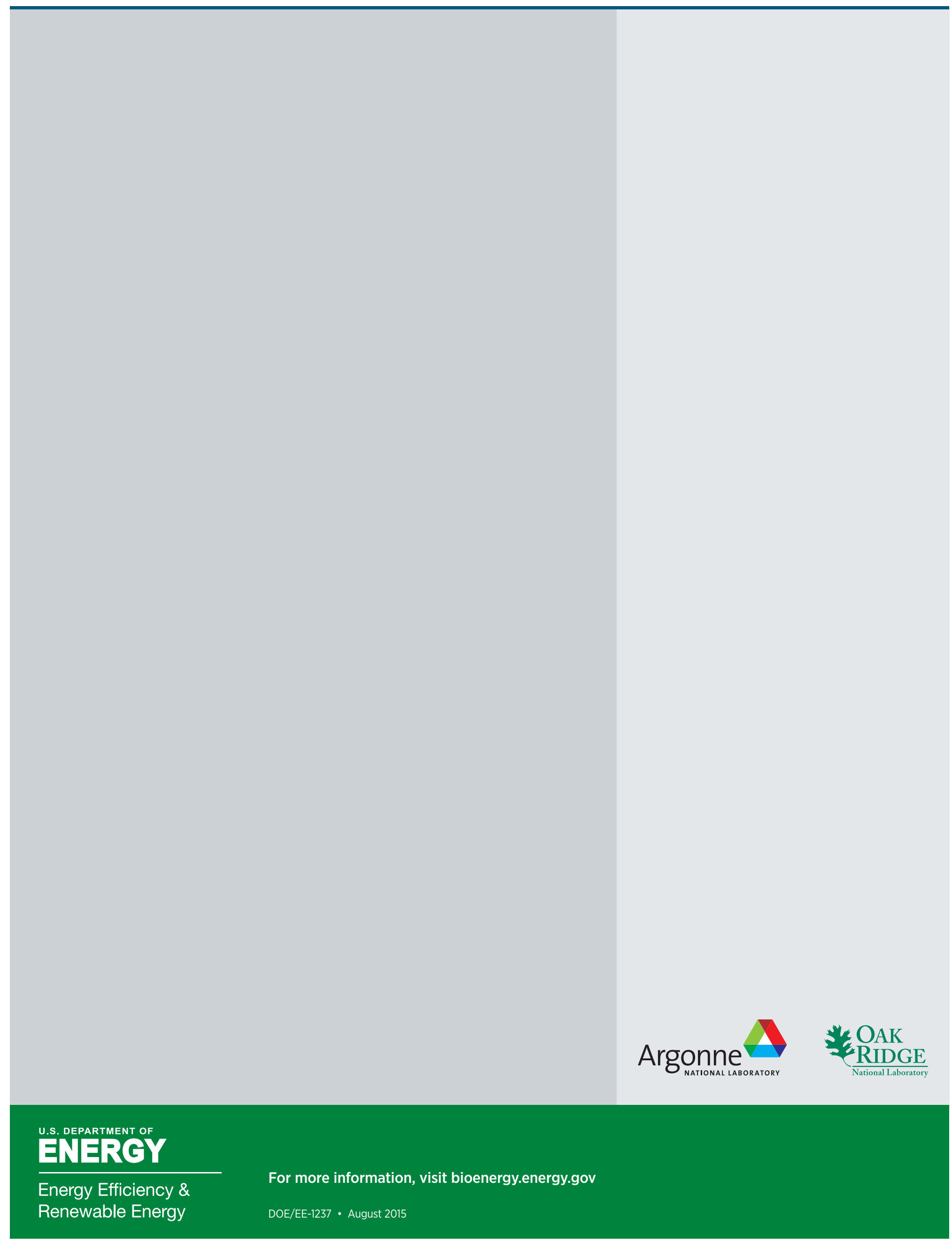

